\title{
Retinoid X receptor beta (RXRB) expression in Sertoli cells controls cholesterol homeostasis and spermiation
}

\author{
Nadège Vernet ${ }^{1,2}$, Christine Dennefeld ${ }^{1,2}$, Muriel Klopfenstein ${ }^{1,2}$, Alberto Ruiz ${ }^{3}$, Dean Bok ${ }^{3}$, \\ Norbert B Ghyselinck ${ }^{1,2}$ and Manuel Mark ${ }^{1,2}$ \\ ${ }^{1}$ Institut de Génétique et de Biologie Moléculaire et Cellulaire (IGBMC), Inserm U596, CNRS UMR7104, IIlkirch \\ F-67400, France, ${ }^{2}$ Université Louis Pasteur, Strasbourg F-67000, France and ${ }^{3}$ Department of Neurobiology, Jules Stein \\ Eye Institute, University of California, Los Angeles 90095-7002, California, USA
}

Correspondence should be addressed to M Mark or N B Ghyselinck at IGBMC, 1 rue Laurent Fries, BP 10142, F-67404 IIIkirch Cedex, CU de Strasbourg, France; Email: manuel.mark@igbmc.fr;

Email: norbert.ghyselinck@igbmc.fr

\begin{abstract}

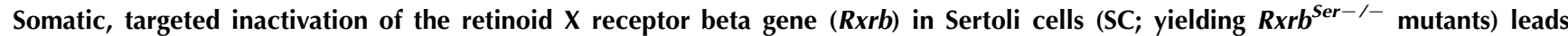
to failure of spermatid release, accumulation of cholesterol esters and, subsequently, testis degeneration. These abnormalities are identical, in their nature and kinetics, to those observed upon inactivating Rxrb in the whole organism, thereby demonstrating that all reproductive functions of RXRB are carried out in SC. The Rxrb $^{\text {Ser-/- }}$ testis degeneration is a consequence of a cholesterol ester cell overload occurring in SC in response to reduced ABCA1- and SCARB1-mediated cholesterol efflux. The failure of spermiation was also reported in mice lacking the retinoic acid (RA) receptor- $\alpha$ (RARA) in SC (Rara ${ }^{\text {Ser- } /-}$ mutants) and represents, in addition, a feature of vitamin A deficiency that can be readily induced in mice lacking the lecithin:retinol acyltransferase ( rrat $^{-/-}$mutants). Altogether, these findings support the conclusion that RXRB heterodimerized with a RA-liganded RARA transduces signals required in SC for spermatid release.

Reproduction (2008) 136 619-626
\end{abstract}

\section{Introduction}

Retinoid X receptors (RXRA, RXRB and RXRG) can heterodimerize with a large variety of nuclear receptors (Szanto et al. 2004). Accordingly, Rxra loss-of-function mutations have pleiotropic effects on embryogenesis (Kastner et al. 1997, Mascrez et al. 1998, 2001, Mark et al. 2006) as well as on homeostasis of adult tissues (Li et al. 2000, 2001, 2005, Imai et al. 2001, 2004, Calléja et al. 2006). By contrast, inactivation of Rxrb in the germline (yielding $R \times r b^{-/-}$mutants, lacking RXRB in the whole organism) results in morphological abnormalities that are restricted to the seminiferous epithelium, namely failure of spermatid release and accumulation of lipids in Sertoli cells (SC; Kastner et al. 1996). Genetic studies in the mouse (Rxrb af2o mutants) have also established that the ligand-dependent transcriptional activation function (AF-2) of RXRB is dispensable for spermiation, while this AF-2 is required in RXRB/LXRB heterodimers to control cholesterol efflux from $S C$ through regulating expression of the membraneassociated ABCA1 transporter (Mascrez et al. 2004). These observations and the fact that vitamin A deficiency does not yield lipid metabolism defects (Ghyselinck et al.
2006) rule out the possibility that retinoic acid (RA) is the ligand activating RXRB in the seminiferous epithelium (Mascrez et al. 2004).

Expression pattern analyses nevertheless left open the possibility that RXRB could exert some functions on testis physiology by acting among in SC (Vernet et al. 2006a), Leydig cells (Gaemers et al. 1998a) or anterior pituitary cells (Krezel et al. 1999). In the present study, we have analyzed the consequences of RXRB ablation only in SC (i.e. in Rxrb ${ }^{\text {Ser- }-}$ mutants). We have also analyzed the reproductive phenotype of mutant mice carrying null alleles of the lecithin:retinol acyltransferase (LRAT) gene ( rrat $^{-/-}$mutants; Ruiz et al. 2007) under conditions of dietary vitamin A deficiency. Our data demonstrate that RXRB acts cell autonomously in SC i) to promote cholesterol efflux and ii) to allow proper spermiation, the process by which the mature spermatids are released into the lumen of the seminiferous tubule. Based on the similarities of the phenotypes displayed by Rxrb ${ }^{\text {Ser-1- }}$ mutants, Rxrb ${ }^{-/-}$mutants (Kastner et al. 1996) and mice lacking the RA-receptor- $\alpha$ (RARA) in SC (Rara ${ }^{\text {Ser-/- }}$ mutants; Vernet et al. 2006b), we conclude that RXRB/RARA heterodimers, in which RARA is activated by $R A$, are instrumental to spermiation. 


\section{Results}

\section{Failure of spermiation is a hallmark of the Rxrb ${ }^{\mathrm{Ser}-/-}$ mutation}

The testes of 4-month-old Rxrb $b^{S e r-/-}$ mutants displayed normal germ cell associations (Fig. $1 \mathrm{~B}, \mathrm{D}, \mathrm{H}$ and $\mathrm{J}$ compare with A, C, G and I). However, numerous mature spermatids did not align at the luminal side of the seminiferous epithelium at stage VII, but remained trapped within the epithelium at stages IX and $\mathrm{X}$ (arrowheads in Fig. 1D, compare with C), indicating a severe failure of spermiation. In addition, all $R \times r b^{\text {Ser- }--}$ seminiferous tubules contained TUNEL-positive cellular debris, whose shapes and cyclical variations strongly supported an origin from phagocytized spermatids (arrowheads in Fig. $1 \mathrm{H}$ and J, compare with G and I; Gehin et al. 2002, Mascrez et al. 2004). On the other hand, similarly low amounts of TUNEL-positive spermatocytes were observed in $R \times r b^{S e r-/-}$ and wild-type (WT) seminiferous tubules (P*, Fig. 1G and data not shown), thereby excluding the occurrence of massive germ cell death upon ablation of RXRB in SC. Therefore, both histological and TUNEL analyses indicate that the failure of spermatid release and subsequent degradation of
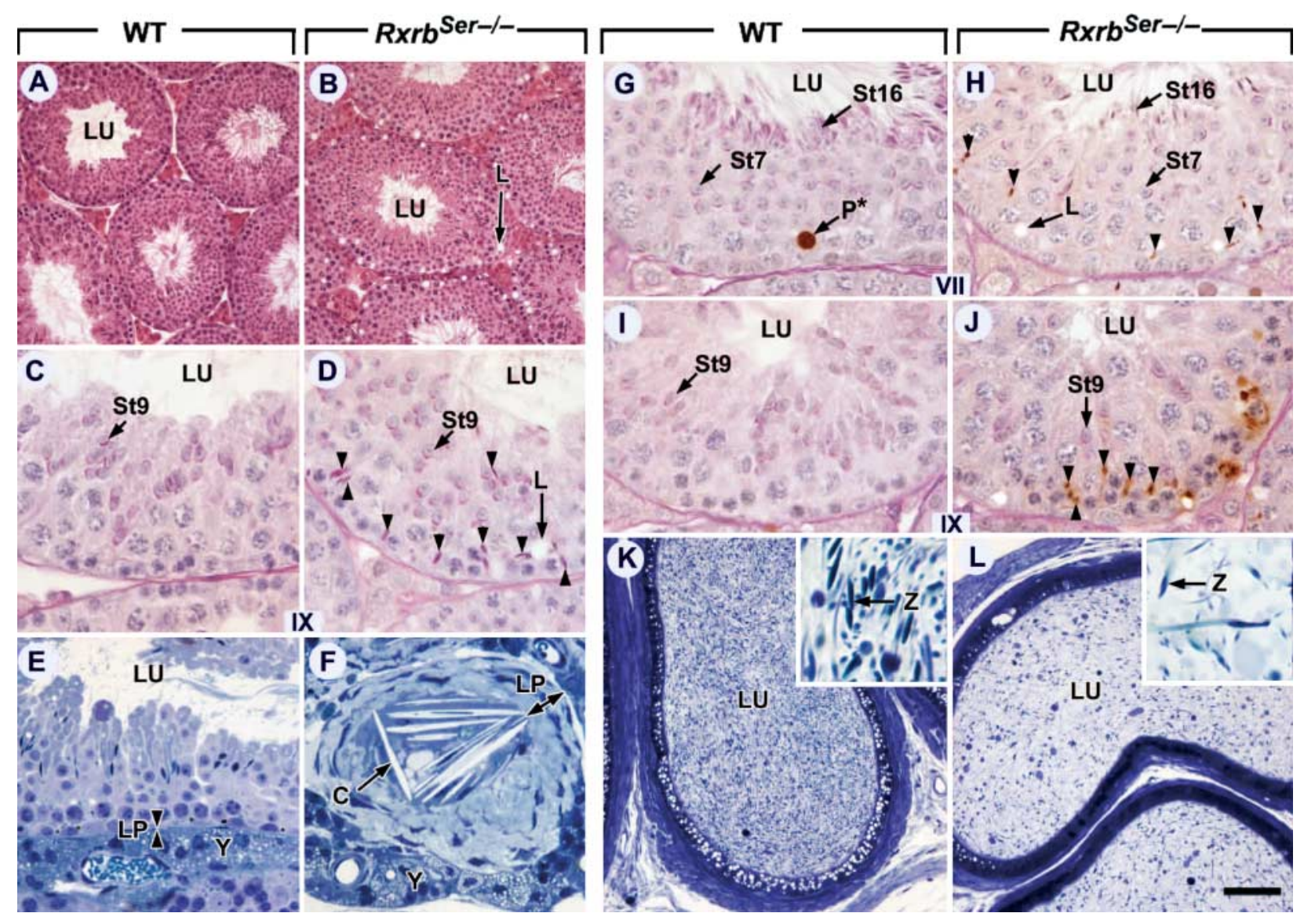

Figure 1 Failure of spermatid release, oligozoospermia and testis degeneration in Rxrb ${ }^{\text {Ser-/- }}$ mutants. Histological sections of testes (A-J) and epididymides (K and L) at 4 (A-D, G-L) and 12 (E and F) months of age. ( $A$ and B) Overview of the seminiferous epithelium prior to the onset of testis degeneration in $R x r b^{\text {Ser- }-}$ mutants; haematoxylin and eosin stain. Note that each 'hole' in the Rxrb ${ }^{\text {Ser- }-}$ seminiferous epithelium corresponds to a large lipid droplet (L) that was extracted during tissue processing. (C and D) Representative examples of stage IX of the seminiferous epithelium cycle; PAS stain. Note that the presence of numerous retained mature spermatids (arrowheads in D) at the periphery of the $R x r b^{S e r-/-}$ seminiferous epithelium. (E and F) Representative aspects of the seminiferous epithelium in old mice after the completion of testis degeneration in $R x r b^{\text {Ser- } /-}$ mutants; toluidine blue stain. The $R x r b^{S e r-1-}$ seminiferous epithelium is restricted to rare SC separated by lipid cholesterol ester crystals. (G-J) TUNEL analysis of WT and Rxrb ${ }^{S e r-/-}$ mutant testes prior to the onset of degeneration; the histological sections were counterstained with PAS. In $R x r b^{\text {Ser- }-}$ testes (in $\mathrm{H}$ ), note that mature (step 16) spermatids at an early phase of their retention (i.e. located at the apical pole of SC and in contact with the lumen of stages VII seminiferous tubules) are TUNEL negative; these spermatids become massively TUNEL positive (arrowheads in J) upon uptake and degradation by SC, suggesting that DNA fragmentation in these cells is a consequence of their degradation by the SC.

Normal apoptotic activity, reflected by the occurrence of TUNEL-positive spermatocytes (P* in G), is indistinguishable in Rxrb ${ }^{\text {Ser- }-1-}$ and WT testes. $\left(\mathrm{K}\right.$ and L) Spermatozoa head profiles (Z) are scarce in $R x r b^{\text {Ser-I- }}$ epididymis when compared with its WT counterpart; toluidine blue stain. C, cholesterol ester crystals; L, lipid droplets or lipid droplet 'ghosts'; LP, lamina propria; LU, lumens of seminiferous tubules or epididymis; P*, apoptotic pachytene spermatocyte; SC, Sertoli cell; Sp7, Sp9 and Sp16 refer to steps of spermatid maturation; Z spermatozoa. Roman numerals designate stages of the seminiferous epithelium cycle. Bar (in L): $80 \mu \mathrm{m}$ (A, B, K and L); $30 \mu \mathrm{m}(\mathrm{C}-\mathrm{J}) ; 10 \mu \mathrm{m}$ (insets in K and L). 
retained spermatids by SC accounts for the marked decrease in the number of epididymal spermatozoa observed in Rxrb $b^{\text {Ser- }-}$ mutants (Z, compare with Fig. $1 \mathrm{~K}$ and $\mathrm{L}$ ). They also provide evidence that inactivating $R \times r b$ solely in SC suffices to recapitulate the oligozoospermia described in Rxrb ${ }^{-1-}$ mutants (Kastner et al. 1996).

\section{Failure of spermiation is a hallmark of an impaired vitamin A signalling pathway}

In mice, a state of post-natal vitamin A deficiency is technically difficult to achieve as WT mice have to be born from parents fed a vitamin A-deficient (VAD) diet to exhibit pathologies (Van Pelt \& de Rooij 1990, Gaemers et al. 1998b; and references therein), and under those circumstances, their seminiferous epithelium may reach some state of vitamin A deficiency before the completion of the first spermatogenic cycle. In contrast to WT mice, mutants carrying null alleles of the gene coding for the blood carrier retinol-binding protein ( $R b p 4^{-1-}$ mutants) are unable to mobilize their retinol liver stores (Quadro et al. 1999, Ghyselinck et al. 2006), and mice carrying null alleles of the LRAT gene ( $\mathrm{rat}^{-/-}$mutants) cannot properly store retinyl esters (Batten et al. 2004, O'Byrne et al. 2005, Ruiz et al. 2007). Therefore, both Rbp4 ${ }^{-1-}$ and $\mathrm{Lrat}^{-/-}$mice are much more vulnerable to dietary vitamin A deficiency than are WT mice (Liu \& Gudas 2005, Quadro et al. 2005), and represent valuable models to study the VAD status in mice. Intriguingly, the failure of spermiation, an early defect of $R b p 4^{-1-}$ mutants fed a VAD diet (Ghyselinck et al. 2006), was reported neither in VAD WT mice nor in other genetic mouse models of vitamin A deficiency (Liu \& Gudas 2005). This raised the question as to whether altered spermiation was a peculiarity of the $R b p 4^{-/}$mutants fed a VAD diet rather than a symptom of vitamin A deficiency in Mus musculus. To distinguish between these possibilities, we investigated the effects of the Lrat knockout on seminiferous epithelium histology.

The $\mathrm{Lrat}^{-1-}$ mutants were fertile when fed a vitamin A sufficient diet $(25000 \mathrm{UI} / \mathrm{kg})$, and their seminiferous epithelium appeared histologically normal. The same applied for $\mathrm{Lrat}^{-1-}$ mutants fed a VAD diet for 4 and 5 weeks (not shown). On the other hand, rrat $^{-1-}$ mutants fed the VAD diet for 6 weeks (VADD6) showed retained mature spermatids at epithelial stages VII to X (arrowheads in Fig. 2B and $\mathrm{D}$ compared with $\mathrm{A}$ and $\mathrm{C}$ ). In addition, VADD6 $\mathrm{Lrat}^{-/-}$seminiferous tubules lacked all pre-leptotene and early meiotic (i.e. leptotene and zygotene) spermatocytes (PR and L, Fig. 2A and C compared with $B$ and $D$ ), while displaying spermatocytes at more advanced stages (i.e. pachytene) and/or spermatids. As this feature is pathognomonic of vitamin A deficiency (Ghyselinck et al. 2006), our data provide definitive evidence that vitamin A (and therefore, RA signalling) is instrumental to spermiation.

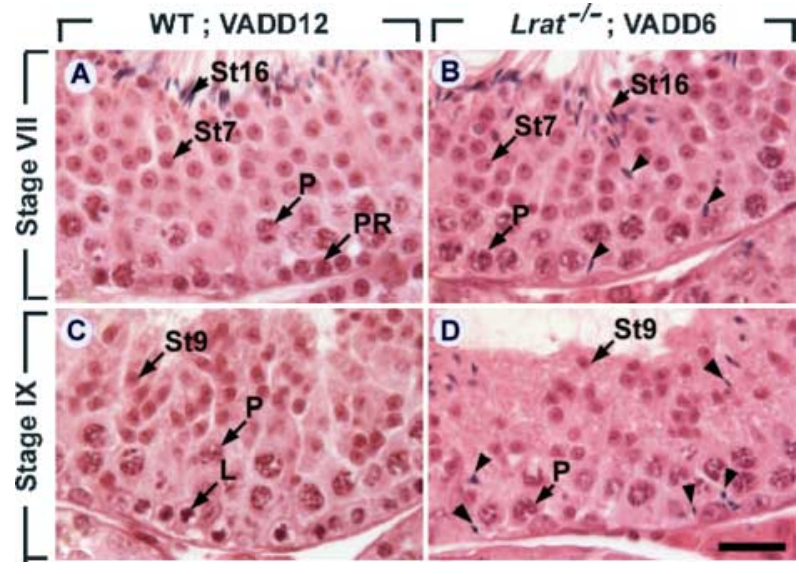

Figure 2 Failure of spermatid release resulting from vitamin A deficiency in the $\mathrm{Lrat}^{-1-}$ mouse model. (A and C) Testes from wild-type (WT) mice fed a vitamin A deficient (VAD) diet for 12 weeks (VADD12) do not show any histological defect. (B and D) By contrast, after 6 weeks on the VAD diet (VADD6), Lrat $^{-/-}$mutants consistently display retained spermatids (arrowheads) at stages VII to X of the seminiferous epithelium cycle. Note also that $\mathrm{Lrat}^{-1-}$ mutants are missing complete layers of pre-meiotic and early meiotic spermatocytes in all seminiferous tubules, which is a hallmark of vitamin A deficiency. Legend: L, P and PR, leptotene pachytene and preleptotene spermatocytes; St7, St9 and St16, step 7, step 9 and step 16 spermatidsrespectively. Arrowheads point to retained mature spermatids. Haematoxylin and eosin stain. Bar (in D): $30 \mu \mathrm{m}(\mathrm{A}-\mathrm{D})$.

The failure of spermiation is also consistently observed in mice lacking RARA in SC ( $\mathrm{Rara}^{\mathrm{Ser}-/-}$ mutants, Vernet et al. 2006b), thereby strongly suggesting that RXRB/ RARA heterodimers are instrumental to spermiation. However, this hypothesis was not genetically validated as we did not find spermiation defects in $R \times r b^{\text {Ser+/- }}$ Rara $^{\text {Ser+/- }}$ testes (three mutants analyzed). In addition, we did not observe any significant increase in the amount of retained spermatids in $\mathrm{Rxr} b^{\mathrm{Ser-} /-} / \mathrm{Rara}^{\mathrm{Ser-}-1}$ compound mutants $(n=3)$ when compared with the single null mutants (data not shown).

\section{The expression of several candidate genes is altered upon ablation of Rxrb in SC}

Spermiation is vulnerable to deficiencies in folliclestimulating hormone $(\mathrm{FSH})$, testosterone or vitamin A (Huang \& Marshall 1983, Saito et al. 2000, Beardsley \& O'Donnell 2003, Ghyselinck et al. 2006). All of these hormonal signalling pathways act via cell-autonomous regulators of SC functions, namely the FSH receptor (FSHR; Dierich et al. 1998, Abel et al. 2000), the androgen receptor (AR; Chang et al. 2004, De Gendt et al. 2004) and the RA receptor- $\alpha$ (RARA; Vernet et al. 2006b). Quantitative RT coupled to PCR amplification (qRT-PCR) using total RNA extracted from the testes of age-matched (9-week-old) $R \times r b^{\text {Ser-1- }}$ and WT males (Fig. 3) revealed that the steady-state levels of i) Rara transcripts were not altered in $R \times r b^{S e r-1-}$ mutant testes, ii) Fshr transcripts were increased by $50 \%$, and iii) $\mathrm{Ar}$ 


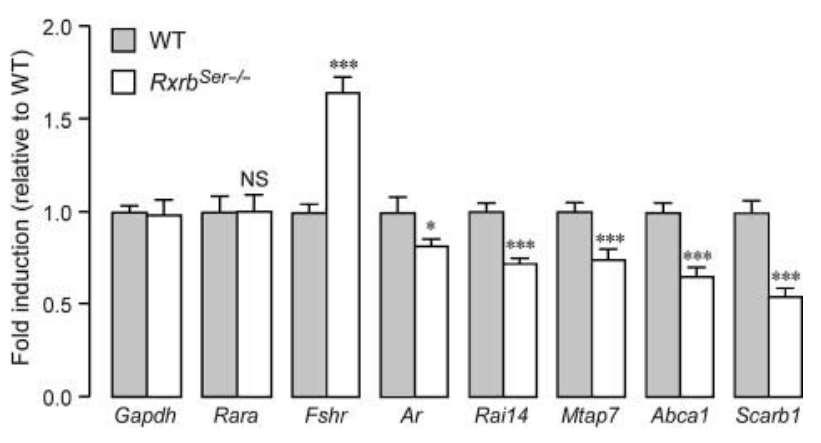

Figure 3 Expression of candidate genes involved in spermiation (Rara, Fshr, Ar) and eventually controlled by RA (Rai14, Mtap7), or involved in cholesterol efflux (Abca1, Scarb1) in the testis of Rxrb ${ }^{\text {Ser- }-1-}$ mutants at 9 weeks of age. Total RNA extracted from testes of $R \times r b^{\text {Ser- }-1-}$ (white bar) and wild-type (WT) littermates (grey bar) was subjected to realtime quantitative RT-PCR analysis for transcripts of the indicated genes. The values (arbitrary units) correspond to the mean amount \pm S.E.M. of RNA transcripts detected in each series $(n=3)$, relative to the amount of Gapdh transcripts, whose expression is not changed upon $R \times r b$ ablation. The asterisks indicate a significant difference $\left({ }^{*} P<0.05\right.$; ${ }^{* * *} P<0.001$; Student's $t$-test). NS, not statistically different.

transcripts exhibited a slight, but significant $(P<0.05)$ decrease, which is probably physiologically relevant owing to the fact that SC represent only a fraction of Ar-expressing somatic cells in the testis (Sar et al. 1993).

We also investigated the expression of the RA-inducible genes Rai14 (Peng et al. 2000, Kutty et al. 2001) and Mtap7 (Komada et al. 2000), whose products are associated with the SC cytoskeleton and thus potentially involved in spermiation. The expression of both genes was significantly $(P<0.001)$ decreased in $R \times r b^{S e r-1-}$ testes at 9 weeks of age (Fig. 3), i.e. prior to the appearance of any sign of testis degeneration.

\section{Progressive accumulation of cholesterol esters and decreased Abca1 and Scarb1 expression in $\mathrm{Rxrb}^{\mathrm{Ser}-/-}$ testes}

Numerous lipid droplets were visible at the periphery of seminiferous tubules in all $R \times r b^{S e r-1-}$ testes, already by the end of puberty (i.e. at 1 month of age, Fig. 4A). They were localized within the cytoplasm of SC, as assessed by electron microscopy (not shown), and they markedly enlarged upon ageing ( $\mathrm{L}$, Fig. $4 \mathrm{~A}-\mathrm{C}$, right panels). By contrast, similar lipid droplets remained small in WT testes (L, Fig. 4A-C, left panels). Thus, with respect to their early appearance, localization and kinetics of enlargement with ageing, the $R \times r b^{\text {Ser- }-}$ lipid droplets are undistinguishable from those of $R \times r b^{-1-}$ testes (Kastner et al. 1996).

The lipid droplets in $R x r b^{\mathrm{Ser}-/-}$ testes were stained positively by histochemical procedures detecting neutral fats ( $\mathrm{L}$ in Fig. 4E, compare with D) and notably cholesterol and its esters ( $\mathrm{L}$ in Fig. 4G, compare with F). Accordingly, thin layer chromatography (TLC) profiles showed a large excess of cholesterol esters in lipid extracts from $R \times r b^{S e r-/-}$ testes, with no increase in triglyceride levels (Fig. 4L). Therefore, lipids extracted from $R \times r b^{\text {Ser-1- }}$ testes contained an increased amount of cholesterol esters as their $R \times r b^{-1-}$ counterparts (Mascrez et al. 2004).

We quantified the expression of the mRNA encoding for ABCA1 and SCARB1, which both promote cellular cholesterol efflux from SC (Selva et al. 2004, Duong et al. 2006, and references therein). In 9-week-old Rxrb $b^{\text {Ser-/- }}$ mutants, the mRNA levels of Abca1 were significantly $(P<0.001)$ decreased by about $40 \%$ (Fig. 3 ). It is worth noting that in younger (i.e. 5-week-old) mutants, Abca1 expression was even further decreased (not shown). Thus, ablating Rxrb solely in SC induces a decrease in Abca1 expression of the same order of magnitude than that generated by a Rxrb loss-of-function mutation in the whole organism (i.e. the germline deletion of the RXRB domain containing the AF-2 function, Rxrb af2o mutants; Mascrez et al. 2004). It additionally significantly decreases $(P<0.001)$ the expression of Scarb1 (Fig. 3). As such a decrease is not observed in $R x r b^{\text {af2o }}$ mutants (Mascrez et al. 2004), it appears that a transcriptionally inactive RXRB (i.e. without its AF-2) can control Scarb1 expression in WT SC.

\section{Fatty degeneration of the testis in old $\mathrm{Rxrb}^{\mathrm{Ser}-/-}$ mutants}

A majority of seminiferous tubule sections in 8-monthold Rxrb ${ }^{\text {Ser-1- }}$ mutants showed normal germ cell associations, but others displayed a loss of germ cell populations resulting from detachment of healthy immature cells (data not shown, see Kastner et al. 1996). The testes from 12-month-old mutants contained only 'tubular ghosts' devoid of all epithelial cells, filled with calcified lipids or with large cholesterol ester crystals and delineated by a thickened, fibrotic lamina propria (compare Fig 1E with F, and data not shown). Thus, seminiferous epithelium degeneration is completed at the same age and exhibits identical morphological features in $R \times r b^{\text {Ser- }-}$ and $R \times r b^{-1-}$ mutants (Kastner et al. 1996 and present report).

\section{Discussion}

\section{RXRB action on spermiation is SC autonomous and mediated by RXRB/RARA heterodimers in which the $R A R$ partner is $R A$ liganded}

$R \times r b^{\text {Ser-/- }}$ mutants display an impaired spermiation as severe as that of $R x r b^{-1-}$ mutants (Kastner et al. 1996), thus demonstrating that RXRB controls mechanisms that allow proper spermatid disengagement on the SC side. We have previously established that spermiation does not require a transcriptionally active RXRB (Mascrez et al. 2004), and have shown that inactivation either in whole mouse or specifically in SC of potential 
heterodimerization partners for RXRB (namely, THRA, THRB, LXRB, PPARA, PPARD or VDR, which are all expressed in SC), does not yield a spermiation failure (Mascrez et al. 2004, and our unpublished results). These observations rule out the involvement, in spermatid release, of a ligand-activated RXRB as well as of heterodimers of RXRB with the nuclear receptors listed
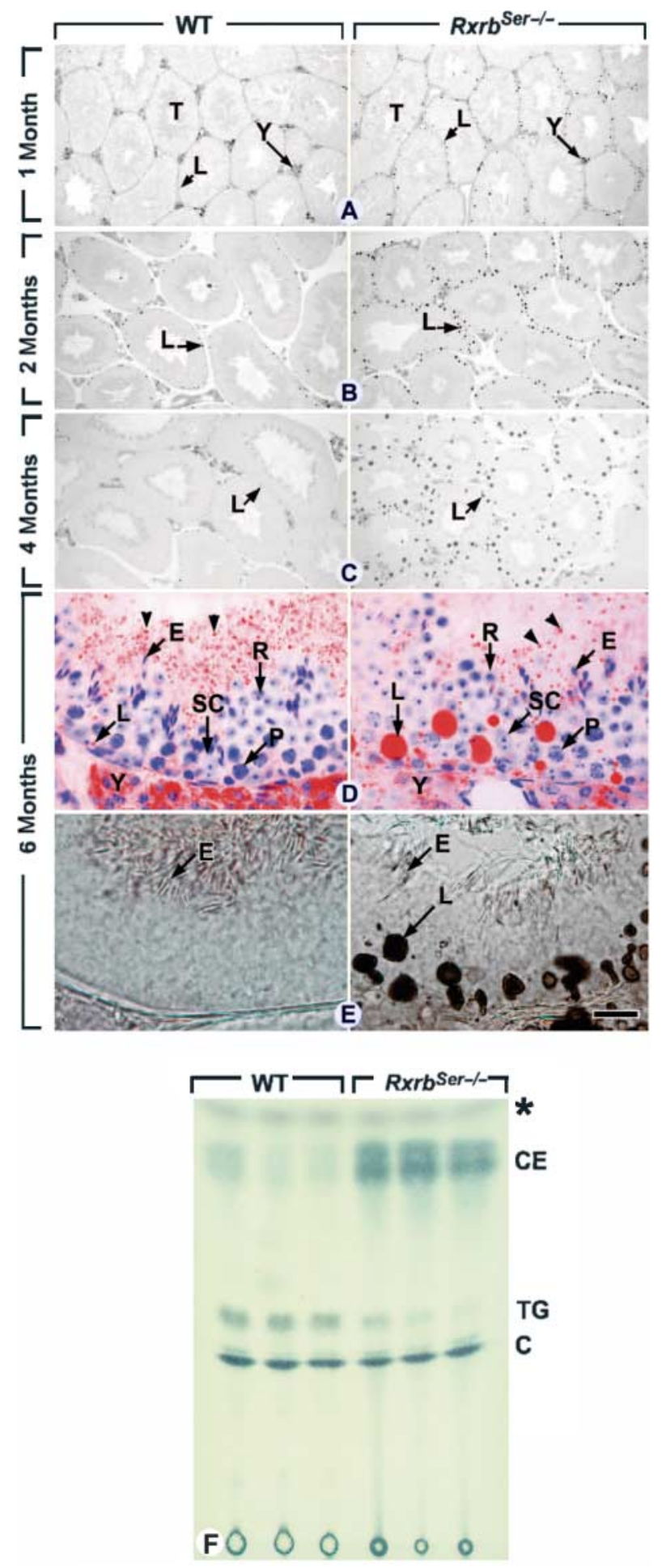

above. On the other hand, the occurrence of a spermiation failure in the $\mathrm{Lrat}^{-1-}$ mouse model of vitamin A deficiency (present report) as well as in the $R b p 4^{-1-}$ mouse model (Ghyselinck et al. 2006) proves that RA, the RAR ligand, is indispensable for spermatid release. As in addition mutant mice lacking RARA in SC also fail to release spermatids (Vernet et al. 2006b), it appears that RXRB/RARA heterodimers in which RARA is RA liganded play a crucial role in spermiation.

Spermiation becomes reduced upon a modest decrease in AR activity (Holdcraft \& Braun 2004). Thus, our demonstration that RXRB promotes the expression of $A r$ in $S C$ suggests that $A R$ may act in spermatid release downstream of the RA-signalling pathway. In contrast to the AR, the FSHR is probably not involved in spermiation under physiological conditions (Dierich et al. 1998, Abel et al. 2000, Wreford et al. 2001). However, our observation that Fshr expression is increased upon inactivation of $R x r b$ in SC, together with the fact that the Fshr promoter contains a binding site for RAR that mediates repression by RA (Xing \& Sairam 2002), supports the view that RXRB/ RARA heterodimers may perform additional functions in SC independently from spermiation.

Spermiation involves a variety of cell adhesion molecules and requires the integrity of the SC cytoskeleton (Russell et al. 1989, Fleming et al. 2003, Lee \& Cheng 2004). In this context, it is noteworthy that inactivating RXRB specifically in SC i) decreases the expression of genes encoding proteins associated with actin microfilaments (i.e. Rai14; Peng et al. 2000, Kutty et al. 2001) or with microtubules (i.e. Mtap7; Komada et al. 2000) and ii) may disorganize the vimentin network through reducing expression of $\operatorname{Ar}$ (Show et al. 2003). On the other hand, expression of espin, a component of SCspermatid ectoplasmic specialization junctional plaques (Bartles et al. 1996), is not altered in Rxrb ${ }^{\text {Ser- - }-}$ mutant testes (data not shown).

Figure 4 Kinetics of lipid accumulation and identification of the lipid types present in $R \times r b^{\text {Ser- }-}$ testes. (A-C) Progressive enlargement of the lipid droplets (black dots) upon ageing in $R \times r b^{\text {Ser-/- }}$ testes; osmium tetroxide stain. ( $D$ and $E$ ) Histochemical characterization of lipids. The hydrophobic dye, oil red $\mathrm{O}$, stains all neutral lipids, including triglycerides and cholesterol esters (in D), whereas the Romieu's modification of the Liebermann-Buchardt's reaction stains specifically cholesterol and its esters (in E). Note that in (D), the DAPI nuclear counterstain was converted to a bright field image (blue false colour) and then superimposed with the oil red O staining (red colour) using Photoshop. (F) Thin layer chromatography of lipids extracted from testes of littermates with the indicated genotypes at the age of 5 weeks; each line corresponds to a distinct mouse. Legend: C, cholesterol; $\mathrm{CE}$, cholesterol esters; E, elongate spermatids; L, lipid droplets in Sertoli cells; P, pachytene spermatocytes; R, round spermatids; SC, Sertoli cells; T, seminiferous tubules; TG, triglycerides; $Y$, Leydig cells. The arrowheads in (D) point to lipid droplets normally present in elongate spermatids and the asterisk in $(\mathrm{F})$ indicates the migration front. Bar (in E): $160 \mu \mathrm{m}$ (A-C); $20 \mu \mathrm{m}$ (D-E). 


\section{Age-related testis degeneration in $\mathrm{Rxrb}^{\mathrm{Ser}-/-}$ mutants results from cholesterol ester accumulation}

The size of the SC lipid droplets, which we have followed over a period of 2 years, does not increase in WT mice after sexual maturity (Fig. 4 and data not shown). By contrast, a pronounced enlargement of the lipid droplets that reach the size of SC nuclei between 6 and 8 months of age is observed in Rxrb $b^{\text {Ser-1- }}$ mutants. As components of the SC cytoskeleton are essential for the maintenance of the seminiferous epithelium (Lee \& Cheng 2004), it is conceivable that these large lipid droplets could mechanically impair organization of SC cytoskeleton, thereby disturbing their adhesion to germ cells and leading to the sloughing of immature spermatids into the lumen of the seminiferous tubules. Additionally or alternatively, it has been proposed that an excess of intracellular cholesterol is toxic through the formation of cholesterol ester crystals, triggering apoptotic pathways, formation of toxic oxysterols and disruption of membrane domains that are crucial for the function of particular enzymes or signalling molecules (Tabas 2002, Cui et al. 2007). The toxicity caused by excess cholesterol could even further promote cholesterol build-up through compromising the mechanism by which cells efflux cholesterol (Feng \& Tabas 2002). Thus, over time, cholesterol accumulation could kill SC yielding tubular ghosts devoid of an epithelium. In any event, cholesterol accumulation in SC can, on its own, account for the age-related testis degeneration in $R \times r b^{S e r-/-}$ mutants.

It is noteworthy that the rate of lipid accumulation in SC is identical between $R \times r b^{-1-}$ and $R \times r b^{\text {Ser- }-1-}$ mutants (Fig. 4A-C; Kastner et al. 1996), but is slower in Rxrb af2o mutants (Mascrez et al. 2004, and our unpublished data). Accordingly, the completion of testis degeneration, manifested by the disappearance of the seminiferous epithelium, occurs earlier (i.e. by 1 year of age) in $\mathrm{Rxrb}^{-1-}$ and $\mathrm{R} \times r b^{\mathrm{Ser-1-}}$ mutants (Kastner et al.
1996, and present report) than in $\operatorname{Rrx} b^{\text {af2o }}$ mutants (Mascrez et al. 2004). The necessity for SC to metabolize larger amounts of cholesterol originating from retained mature spermatids in $\mathrm{Rxrb}^{-/-}$and $\mathrm{Rxrb} \mathrm{Ser-1-}^{-}$mutants and the significant decrease in the expression of Scarb1 in $R \times r b^{S e r-1-}$ mutants, but not in Rxrb ${ }^{\text {af2o }}$ mutants, can both account for these differences.

\section{Materials and Methods}

\section{Mice}

All mice, with a mixed C57BL/6-129/Sv (50\%-50\%) genetic background, were housed in an animal facility licensed by the French Ministry of Agriculture (agreement N'B67-218-5) and all animal experiments were supervised by NBG (agreement $\left.\mathrm{N}^{\circ} 67-205\right)$, in compliance with the European legislation on care and use of laboratory animals. The breeding diet (D03) contained $25000 \mathrm{UI}$ of vitamin A per kg (UAR, Villemoisson sur Orge, France). The VAD diet (TD86143) was purchased from Harlan (Gannat, France) and provided ad libitum. Food consumption was identical between WT and mutants (not shown). For depletion studies, mice ( $n=4$ in each groups) were fed the breeding diet from weaning to 6 weeks of age, and then the VAD diet for the indicated number of weeks.

Mice bearing loxP-flanked (floxed) Rxrb gene $\left(R x r b^{+/ L 2}\right.$; $\mathrm{Li}$ et al. 2005) and Amh-Cre transgenic mice (Amh-Cre ${ }^{\mathrm{tg} / \mathrm{O}}$; Lécureuil et al. 2002) were genotyped as described. To specifically inactivate Rxrb gene in SC, females carrying two floxed alleles of $R x r b$ (i.e. $R \times r b^{L 2 / L 2}$ females) were crossed with males bearing both the Amh-Cre transgene and one floxed allele of $R x r b$ (i.e. Amh-Cre $e^{t g /} / R x r b^{+/ L 2}$ males). These crosses generated males in which $R x r b$ was inactivated in SC (i.e. Amh-Cre ${ }^{t g} /$ / $\left.R \times r b^{L 2 / L 2}\right)$; these mice were referred to as $R \times r b^{S e r-1-}$ mutants. They also generated $R \times r b^{L 2 / L 2}$ and $R \times r b^{+/ L 2}$ control males, which did not display histological defects and were referred to as WT mice. Mice lacking LRAT ( $\mathrm{Lrat}^{-/-}$mutants) were characterized previously. They were genotyped as described (Ruiz et al. 2007).

Table 1 Sequence of primers used for quantitative RT-PCR amplifications.

\begin{tabular}{|c|c|c|c|c|}
\hline Gene & Accession & Primers (forward and reverse) & Position (nt) & Size $(\mathrm{nt})$ \\
\hline Abca1 & NM_013454 & $\begin{array}{l}\text { 5'-AGCCAGAAGGGAGTGTCAGA-3' } \\
\text { 5'-CATGCCATCTCGGTAAACCT-3 }^{\prime}\end{array}$ & $\begin{array}{l}2955-2974 \\
3056-3037\end{array}$ & 102 \\
\hline$A r$ & NM_013476 & $\begin{array}{l}\text { 5'-GGACCATGTTTTACCCATCG-3' }^{\prime} \\
5^{\prime} \text {-TCGTTTCTGCTGGCACATAG-3' }\end{array}$ & $\begin{array}{l}1601-1620 \\
1771-1752\end{array}$ & 171 \\
\hline Fshr & NM_013523 & 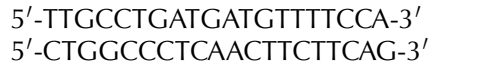 & $\begin{array}{l}688-707 \\
803-784\end{array}$ & 116 \\
\hline Gapdh & NM_008084 & $\begin{array}{l}\text { 5'-CAAGGTCATCCATGACAACTTTG-3' } \\
5^{\prime} \text {-GGCCATCCACAGTCTTCTGG-3' }\end{array}$ & $\begin{array}{l}527-549 \\
615-596\end{array}$ & 89 \\
\hline Mtap7 & NM_008635 & $\begin{array}{l}5^{\prime} \text {-CAGAGGAGGCTACGAGGTTG-3' } \\
5^{\prime} \text {-ACGGGCCAATTCCTCTATCT-3' }\end{array}$ & $\begin{array}{l}1470-1489 \\
1594-1575\end{array}$ & 125 \\
\hline Rai14 & NM_030690 & $\begin{array}{l}5^{\prime} \text {-GGATGTGACTGCCCAAGATT-3' } \\
5^{\prime} \text {-CCCCGAGTTGTCAATGTTCT-3' }\end{array}$ & $\begin{array}{l}472-491 \\
598-579\end{array}$ & 127 \\
\hline Rara & NM_009024 & $\begin{array}{l}\text { 5'-CCAGCTTCCAGTCAGTGGTTA-3' } \\
\text { 5'-TGCTCTGGGTCTCGATGGT-3' }^{\prime}\end{array}$ & $\begin{array}{l}695-715 \\
753-735\end{array}$ & 59 \\
\hline Scarb1 & NM_016741 & $\begin{array}{l}5^{\prime} \text {-СTTCATGACACCCGAATCCT-3' } \\
5^{\prime} \text {-CCCGTTGGCAAACAGAGTAT-3' }\end{array}$ & $\begin{array}{l}984-1003 \\
1125-1106\end{array}$ & 142 \\
\hline
\end{tabular}

The gene names, the accession numbers, the forward (upper line) and reverse (lower line) primers, their positions in the sequences and the sizes of the amplified fragments are indicated. nt, nucleotide. 


\section{Histology, histochemistry and TUNEL assays}

Histological observations were repeated on three to four males per genotype and age group. Staining of histological sections with haematoxylin and eosin, periodic acid Schiff (PAS), osmium tetroxide, toluidine blue and oil red $\mathrm{O}$, and histochemical detection of cholesterol esters were as described (Mark et al. 2007). For detection of apoptotic cells (TUNEL assays), testis samples were fixed in $4 \%(\mathrm{w} / \mathrm{v})$ paraformaldehyde in PBS for $16 \mathrm{~h}$ at $4{ }^{\circ} \mathrm{C}$, then embedded in paraffin. TUNEL-positive cells were detected using the In Situ Cell Death Detection Kit, peroxydase (Roche), and the sections were counterstained with PAS.

\section{TLC of lipid extracts}

Lipids from testes (three different animals for each genotype) were extracted using the Bligh and Dyer procedure, dissolved in $0.5 \mathrm{ml}$ methanol-chloroform $(1: 2)$, loaded onto TLC plates (Machery Nagel, Hoerdt, France) that were run in heptanediethyl ether-acetic acid $(7: 2: 1)$ for $5 \mathrm{~min}$, then in heptane for $10 \mathrm{~min}$, and revealed by molybdatophosphoric acid staining. TLC analyses were repeated three times. Standard lipids were from Sigma.

\section{Analysis of RNA}

Total RNA was prepared using Trizol reagent (Invitrogen Life Technologies). Quantitative analysis of RNA was carried out by two step RT coupled to quantitative real-time PCR using a LightCycler 1.5 (Roche Molecular Biochemicals). Reverse transcription of $2 \mu \mathrm{g}$ total RNA followed by PCR amplification of cDNAs were performed using QuantiTect Reverse Transcription and QuantiTect SYBR Green PCR Kits respectively, according to the manufacturer's instructions (Qiagen). Conditions were 45 cycles with denaturation for $15 \mathrm{~s}$ at $95^{\circ} \mathrm{C}$, annealing for $15 \mathrm{~s}$ at $60^{\circ} \mathrm{C}$ and elongation for $15 \mathrm{~s}$ at $72{ }^{\circ} \mathrm{C}$. Each cDNA sample was tested in triplicate. The transcript levels were normalized relative to that of the glyceraldehyde-3-phosphate dehydrogenase transcripts. Primers were as indicated in Table 1. Data were analysed using Student's $t$-test.

\section{Declaration of interest}

The authors declare that there is no conflict of interest that could be perceived as prejudicing the impartiality of the research reported.

\section{Funding}

This work was supported by the Fondation pour la Recherche Médicale (FRM, grant number DEQ20071210544) and by funds from the Centre National de la Recherche Scientifique (CNRS), the Institut National de la Santé et de la Recherche Médicale (INSERM) and the Hôpital Universitaire de Strasbourg. Nadège Vernet was supported by an Association pour la Recherche sur le Cancer (ARC) fellowship.

\section{Acknowledgements}

We thank F Guillou (INRA, Nouzilly, France) for providing us the Amh-Cre transgenic line, D Metzger and $\mathrm{P}$ Chambon (IGBMC, Strasbourg, France) for Rxrb ${ }^{+/ L 2}$ mice, and B Féret and $\mathrm{N}$ Messaddeq for their technical assistance.

\section{References}

Abel MH, Wootton AN, Wilkins V, Huhtaniemi I, Knight PG \& Charlton HM 2000 The effect of a null mutation in the follicle-stimulating hormone receptor gene on mouse reproduction. Endocrinology 141 1795-1803.

Bartles JR, Wierda A \& Zheng L 1996 Identification and characterization of espin, an actin-binding protein localized to the F-actin-rich junctional plaques of Sertoli cell ectoplasmic specializations. Journal of Cell Science 109 1229-1239.

Batten ML, Imanishi Y, Maeda T, Tu DC, Moise AR, Bronson D, Possin D, Van Gelder RN, Baehr W \& Palczewski K 2004 Lecithin-retinol acyltransferase is essential for accumulation of all-trans-retinyl esters in the eye and in the liver. Journal of Biological Chemistry 279 10422-10432.

Beardsley A \& O'Donnell L 2003 Characterization of normal spermiation and spermiation failure induced by hormone suppression in adult rats. Biology of Reproduction 68 1299-1307.

Calléja C, Messaddeq N, Chapellier B, Yang H, Krezel W, Li M, Metzger D, Mascrez B, Ohta K, Kagechika H et al. 2006 Genetic and pharmacological evidence that a retinoic acid cannot be the RXR-activating ligand in mouse epidermis keratinocytes. Genes and Development 20 1525-1538.

Chang C, Chen YT, Yeh SD, Xu Q, Wang RS, Guillou F, Lardy H \& Yeh S 2004 Infertility with defective spermatogenesis and hypotestosteronemia in male mice lacking the androgen receptor in Sertoli cells. PNAS 101 6876-6881.

Cui D, Thorp E, Li Y, Wang N, Yvan-Charvet L, Tall AR \& Tabas I 2007 Pivotal advance: macrophages become resistant to cholesterol-induced death after phagocytosis of apoptotic cells. Journal of Leukocyte Biology 82 1040-1050.

Dierich A, Sairam MR, Monaco L, Fimia GM, Gansmuller A, LeMeur M \& Sassone-Corsi P 1998 Impairing follicle-stimulating hormone (FSH) signaling in vivo: targeted disruption of the FSH receptor leads to aberrant gametogenesis and hormonal imbalance. PNAS 95 13612-13617.

Duong M, Collins HL, Jin W, Zanotti I, Favari E \& Rothblat GH 2006 Relative contributions of ABCA1 and SR-BI to cholesterol efflux to serum from fibroblasts and macrophages. Arteriosclerosis, Thrombosis, and Vascular Biology 26 541-547.

Feng B \& Tabas I 2002 ABCA1-mediated cholesterol efflux is defective in free cholesterol-loaded macrophages. Mechanism involves enhanced ABCA1 degradation in a process requiring full NPC1 activity. Journal of Biological Chemistry 277 43271-43280.

Fleming SL, Shank PR \& Boekelheide K $2003 \gamma$-Tubulin overexpression in Sertoli cells in vivo. II: retention of spermatids, residual bodies, and germ cell apoptosis. Biology of Reproduction 69 322-330.

Gaemers IC, van Pelt AM, van der Saag PT, Hoogerbrugge JW, Themmen AP \& de Rooij DG 1998a Differential expression pattern of retinoid X receptors in adult murine testicular cells implies varying roles for these receptors in spermatogenesis. Biology of Reproduction 58 1351-1356.

Gaemers IC, Sonneveld E, van Pelt AM, Schrans BH, Themmen AP, van der Saag PT \& de Rooij DG 1998b The effect of 9-cis retinoic acid on proliferation and differentiation of a spermatogonia and retinoid receptor gene expression in the vitamin A-deficient mouse testis. Endocrinology 139 4269-4276.

Gehin M, Mark M, Dennefeld C, Dierich A, Gronemeyer H \& Chambon P 2002 The function of TIF2/GRIP1 in mouse reproduction is distinct from those of SRC-1 and p/CIP. Molecular and Cellular Biology 22 5923-5937.

De Gendt K, Swinnen JV, Saunders PT, Schoonjans L, Dewerchin M, Devos A, Tan K, Atanassova N, Claessens F, Lécureuil C et al. 2004 A Sertoli cell-selective knockout of the androgen receptor causes spermatogenic arrest in meiosis. PNAS 101 1327-1332. 
Ghyselinck NB, Vernet N, Dennefeld C, Giese N, Nau H, Chambon P, Viville S \& Mark M 2006 Retinoids and spermatogenesis: lessons from mutant mice lacking the plasma retinol binding protein. Developmental Dynamics 235 1608-1622.

Holdcraft RW \& Braun RE 2004 Androgen receptor function is required in Sertoli cells for the terminal differentiation of haploid spermatids. Development 131 459-467.

Huang HF \& Marshall GR 1983 Failure of spermatid release under various vitamin A states - an indication of delayed spermiation. Biology of Reproduction 28 1163-1172.

Imai T, Jiang M, Kastner P, Chambon P \& Metzger D 2001 Selective ablation of retinoid $X$ receptor alpha in hepatocytes impairs their lifespan and regenerative capacity. PNAS 98 4581-4586.

Imai T, Takakuwa R, Marchand S, Dentz E, Bornert JM, Messaddeq N, Wendling O, Mark M, Desvergne B, Wahli W et al. 2004 Peroxisome proliferator-activated receptor gamma is required in mature white and brown adipocytes for their survival in the mouse. PNAS 101 4543-4547.

Kastner P, Mark M, Leid M, Gansmuller A, Chin W, Grondona JM, Décimo D, Krezel W, Dierich A \& Chambon P 1996 Abnormal spermatogenesis in RXR beta mutant mice. Genes and Development 10 80-92.

Kastner P, Mark M, Ghyselinck N, Krezel W, Dupé V, Grondona JM \& Chambon P 1997 Genetic evidence that the retinoid signal is transduced by heterodimeric RXR/RAR functional units during mouse development. Development 124 313-326.

Komada M, McLean DJ, Griswold MD, Russell LD \& Soriano P 2000 E-MAP-115, encoding a microtubule-associated protein, is a retinoic acid-inducible gene required for spermatogenesis. Genes and Development 14 1332-1342.

Krezel W, Kastner P \& Chambon P 1999 Differential expression of retinoid receptors in the adult mouse central nervous system. Neuroscience $\mathbf{8 9}$ 1291-1300.

Kutty RK, Kutty G, Samuel W, Duncan T, Bridges CC, El-Sherbeeny A, Nagineni CN, Smith SB \& Wiggert B 2001 Molecular characterization and developmental expression of NORPEG, a novel gene induced by retinoic acid. Journal of Biological Chemistry $2762831-2840$.

Lécureuil C, Fontaine I, Crepieux P \& Guillou F 2002 Sertoli and granulosa cell-specific Cre recombinase activity in transgenic mice. Genesis 33 114-148.

Lee NP \& Cheng CY 2004 Ectoplasmic specialization, a testis-specific cellcell actin-based adherens junction type: is this a potential target for male contraceptive development? Human Reproduction Update 10 349-369.

Li M, Indra AK, Warot X, Brocard J, Messaddeq N, Kato S, Metzger D \& Chambon P 2000 Skin abnormalities generated by temporally controlled RXRalpha mutations in mouse epidermis. Nature 407 633-636.

Li M, Chiba H, Warot X, Messaddeq N, Gérard C, Chambon P \& Metzger D 2001 RXR-alpha ablation in skin keratinocytes results in alopecia and epidermal alterations. Development 128 675-688.

Li M, Messaddeq N, Teletin M, Pasquali JL, Metzger D \& Chambon P 2005 Retinoid $X$ receptor ablation in adult mouse keratinocytes generates an atopic dermatitis triggered by thymic stromal lymphopoietin. PNAS 102 14795-14800.

Liu L \& Gudas LJ 2005 Disruption of the lecithin:retinol acyltransferase gene makes mice more susceptible to vitamin A deficiency. Journal of Biological Chemistry 280 40226-40234.

Mark M, Ghyselinck NB \& Chambon P 2006 Function of retinoid nuclear receptors: lessons from genetic and pharmacological dissections of the retinoic acid signaling pathway during mouse embryogenesis. Annual Review of Pharmacology and Toxicology 46 451-480.

Mark M, Teletin M, Antal C, Wendling O, Auwerx J, Heikkinen S, Khetchoumian K, Argmann CA \& Dgheem M 2007 Histopathology in mouse metabolic investigations. Current Protocols in Molecular Biology. Chapter 29: Unit 29B.4. DOI: 10.1002/0471142727.mb29b04s78.

Mascrez B, Mark M, Dierich A, Ghyselinck NB, Kastner P \& Chambon P 1998 The RXRalpha ligand-dependent activation function 2 (AF-2) is important for mouse development. Development 125 4691-4707.

Mascrez B, Mark M, Krezel W, Dupé V, LeMeur M, Ghyselinck NB \& Chambon P 2001 Differential contributions of AF-1 and AF-2 activities to the developmental functions of RXR alpha. Development $\mathbf{1 2 8}$ 2049-2062.
Mascrez B, Ghyselinck NB, Watanabe M, Annicotte JS, Chambon P, Auwerx J \& Mark M 2004 Ligand-dependent contribution of RXRbeta to cholesterol homeostasis in Sertoli cells. EMBO Reports 5 285-290.

O'Byrne SM, Wongsiriroj N, Libien J, Vogel S, Goldberg IJ, Baehr W, Palczewski K \& Blaner WS 2005 Retinoid absorption and storage is impaired in mice lacking lecithin:retinol acyltransferase (LRAT). Journal of Biological Chemistry 280 35647-35657.

van Pelt AM \& De Rooij DG 1990 The origin of the synchronization of the seminiferous epithelium in vitamin A-deficient rats after vitamin A replacement. Biology of Reproduction 42 677-682.

Peng YF, Mandai K, Sakisaka T, Okabe N, Yamamoto Y, Yokoyama S, Mizoguchi A, Shiozaki H, Monden M \& Takai Y 2000 Ankycorbin: a novel actin cytoskeleton-associated protein. Genes to Cells $\mathbf{5}$ 1001-1008.

Quadro L, Blaner WS, Salchow DJ, Vogel S, Piantedosi R, Gouras P, Freeman S, Cosma MP, Colantuoni V \& Gottesman ME 1999 Impaired retinal function and vitamin A availability in mice lacking retinol-binding protein. EMBO Journal 18 4633-4644.

Quadro L, Hamberger L, Gottesman ME, Wang F, Colantuoni V, Blaner WS \& Mendelsohn CL 2005 Pathways of vitamin A delivery to the embryo: insights from a new tunable model of embryonic vitamin A deficiency. Endocrinology 146 4479-4490.

Ruiz A, Ghyselinck NB, Mata N, Nusinowitz S, Lloyd M, Dennefeld C, Chambon P \& Bok D 2007 Somatic ablation of the Lrat gene in the mouse retinal pigment epithelium drastically reduces its retinoid storage. Investigative Ophthalmology \& Visual Science 48 5377-5387.

Russell LD, Saxena NK \& Turner TT 1989 Cytoskeletal involvement in spermiation and sperm transport. Tissue and Cell 21 361-379.

Saito K, O'Donnell L, McLachlan RI \& Robertson DM 2000 Spermiation failure is a major contributor to early spermatogenic suppression caused by hormone withdrawal in adult rats. Endocrinology 141 2779-2785.

Sar M, Hall SH, Wilson EM \& French FS 1993 Androgen regulation of Sertoli cells. In The Sertoli Cell, pp 509-516. Eds ID Russell \& MD Griswold. Clearwater: Cache River Press.

Selva DM, Hirsch-Reinshagen V, Burgess B, Zhou S, Chan J, Mclsaac S, Hayden MR, Hammond GL, Vogl AW \& Wellington CL 2004 The ATPbinding cassette transporter 1 mediates lipid efflux from Sertoli cells and influences male fertility. Journal of Lipid Research 45 1040-1050.

Show MD, Anway MD, Folmer JS \& Zirkin BR 2003 Reduced intratesticular testosterone concentration alters the polymerization state of the Sertoli cell intermediate filament cytoskeleton by degradation of vimentin. Endocrinology 144 5530-5536.

Szanto A, Narkar V, Shen Q, Uray IP, Davies PJ \& Nagy L 2004 Retinoid X receptors: X-ploring their (patho)physiological functions. Cell Death and Differentiation 11 S126-S143.

Tabas I 2002 Consequences of cellular cholesterol accumulation: basic concepts and physiological implications. Journal of Clinical Investigation 110 905-911.

Vernet N, Dennefeld C, Rochette-Egly C, Oulad-Abdelghani M, Chambon P, Ghyselinck NB \& Mark M 2006a Retinoic acid metabolism and signaling pathways in the adult and developing mouse testis. Endocrinology 147 96-110.

Vernet N, Dennefeld C, Guillou F, Chambon P, Ghyselinck NB \& Mark M $2006 b$ Prepubertal testis development relies on retinoic acid but not rexinoid receptors in Sertoli cells. EMBO Journal 25 5816-5825.

Wreford NG, Rajendra Kumar T, Matzuk MM \& de Kretser DM 2001 Analysis of the testicular phenotype of the follicle-stimulating hormone beta-subunit knockout and the activin type II receptor knockout mice by stereological analysis. Endocrinology 142 2916-2920.

Xing W \& Sairam MR 2002 Retinoic acid mediates transcriptional repression of ovine follicle-stimulating hormone receptor gene via a pleiotropic nuclear receptor response element. Biology of Reproduction 67 204-211.

Received 26 May 2008

First decision 25 June 2008

Accepted 18 August 2008 